\title{
Calcium plus vitamin $D$ supplementation affects pregnancy outcomes in gestational diabetes: randomized, double-blind, placebo-controlled trial
}

\author{
Maryam Karamali ${ }^{1}$, Zatollah Asemi ${ }^{2, *}$, Maedeh Ahmadi-Dastjerdi ${ }^{1}$ and \\ Ahmad Esmaillzadeh ${ }^{3,4}$ \\ 'Department of Gynecology and Obstetrics, School of Medicine, Arak University of Medical Sciences, Arak, Islamic \\ Republic of Iran: ${ }^{2}$ Department of Nutrition, Research Center for Biochemistry and Nutrition in Metabolic Diseases, \\ Kashan University of Medical Sciences, Kashan, Islamic Republic of Iran: ${ }^{3}$ Food Security Research Center, Isfahan \\ University of Medical Sciences, Isfahan, Islamic Republic of Iran: ${ }^{4}$ Department of Community Nutrition, School of \\ Nutrition and Food Science, Isfahan University of Medical Sciences, Isfahan, Islamic Republic of Iran
}

Submitted 14 November 2014: Final revision received 4 February 2015: Accepted 6 February 2015: First published online 20 March 2015

\begin{abstract}
Objective: The present study was designed to assess the effects of Ca + vitamin D supplementation on pregnancy outcomes in women with gestational diabetes mellitus (GDM).

Design: A randomized, double-blind, placebo-controlled trial was conducted among sixty women with GDM. Participants were divided into two groups to receive $\mathrm{Ca}+$ vitamin $\mathrm{D}$ supplements or placebo. Individuals in the $\mathrm{Ca}+$ vitamin $\mathrm{D}$ group ( $n$ 30) received $1000 \mathrm{mg} \mathrm{Ca} / \mathrm{d}$ and two pearls containing $1250 \mu \mathrm{g}$ (50 $000 \mathrm{IU}$ ) of cholecalciferol (vitamin $\mathrm{D}_{3}$ ) during the intervention (one at study baseline and another at day 21 of the intervention); those in the placebo group ( $n$ 30) received two placebos of vitamin D at the mentioned times and placebos of Ca every day for 6 weeks. Pregnancy outcomes were determined.

Setting: A urban community setting in Arak, Iran.

Subjects: Sixty women with GDM and their newborns, living in Arak, Iran were enrolled.

Results: Women treated with $\mathrm{Ca}+$ vitamin $\mathrm{D}$ had a significant decrease in caesarean section rate $(23.3 \% v .63 .3 \%, P=0.002)$ and maternal hospitalization ( $0 v$ v $13.3 \%, P=0.03$ ) compared with those receiving placebo. In addition, newborns of GDM women randomized to $\mathrm{Ca}+$ vitamin $\mathrm{D}$ had no case of macrosomia, while the prevalence of macrosomia among those randomized to placebo was $13.3 \%(P=0.03)$. Lower rates of hyperbilirubinaemia $(20.0 \% v$. $56.7 \%, P=0.03)$ and hospitalization $(20.0 \% v .56 .7 \%, P=0.03)$ were also seen in the supplemented group of newborns than in the placebo group.

Conclusions: Ca + vitamin D supplementation for 6 weeks among pregnant women with GDM led to decreased caesarean section rate and maternal hospitalization, and decreased macrosomia, hyperbilirubinaemia and hospitalization in newborns.
\end{abstract}

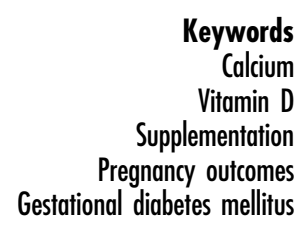

Gestational diabetes mellitus (GDM) is defined as any degree of hyperglycaemia or glucose intolerance with first recognition during pregnancy ${ }^{(1)}$. The worldwide prevalence of GDM varies considerably; some reports indicated that it occurs in up to $14 \%$ of all pregnancies ${ }^{(2)}$. GDM and maternal obesity are independently associated with several adverse complications ${ }^{(3)}$. The Hyperglycemia and Adverse Pregnancy Outcome (HAPO) study demonstrated a positive linear relationship between fasting and post-load glucose concentrations and adverse perinatal outcomes including fetal size, adiposity and hyperinsulinism ${ }^{(4)}$. In addition, GDM is associated with increased risk of adverse maternal and fetal outcomes ${ }^{(5)}$.

Medical nutrition therapy, including use of a lowglycaemic-index diet and the Dietary Approaches to Stop Hypertension (DASH) eating plan ${ }^{(6)}$, have been suggested for prevention and management of $\mathrm{GDM}^{(7)}$. Beyond lifestyle interventions, Ca or vitamin D supplementation has also been proposed as an approach that could improve pregnancy outcomes in GDM patients ${ }^{(8,9)}$. Previous studies 
have shown that circulating $\mathrm{Ca}$ and vitamin $\mathrm{D}$ levels are strongly associated with fasting insulin and post-challenge glucose concentrations, GDM and pregnancy outcomes ${ }^{(10,11)}$. In a systematic review, Ca supplementation $(\geq 1 \mathrm{~g} / \mathrm{d})$ was associated with a significant reduction in the risk of pre-eclampsia, preterm birth and occurrence of the composite outcome 'maternal death or serious morbidity"(12). Furthermore, vitamin D deficiency during pregnancy was associated with increased primary caesarean section rate $^{(13)}$. However, some reports have shown that $\mathrm{Ca}$ and vitamin D supplementation did not affect pregnancy outcomes in mothers without $\mathrm{GDM}^{(14,15)}$.

Vitamin D and Ca might affect pregnancy outcomes through influencing skeletal composition and smooth muscle strength ${ }^{(13)}$ as well as metabolic profiles ${ }^{(16)}$. Ca and vitamin $\mathrm{D}$ have been suggested to act jointly rather than independently. Previous reports have shown that joint supplementation is much more efficient in influencing metabolic profiles than single Ca or vitamin D supplementation $^{(17,18)}$. Considering the high prevalence of vitamin D deficiency and insufficient dietary intakes of Ca among Iranian pregnant women ${ }^{(19,20)}$, along with the beneficial effects of joint supplementation on metabolic profiles in GDM patients, we hypothesized that combined $\mathrm{Ca}$ and vitamin D supplementation might influence pregnancy outcomes in GDM patients. The current study was therefore conducted to investigate the effects of $\mathrm{Ca}+$ vitamin D supplementation on pregnancy outcomes among women with GDM.

\section{Methods}

\section{Participants}

We conducted a randomized, double-blind, placebocontrolled study in Arak, Iran, during March-July 2014 which was registered on the Iranian registry of clinical trials website (IRCT201407115623N23). For estimating sample size, we used a randomized clinical study sample size formula where type one $(\alpha)$ and type two errors $(\beta)$ were 0.05 and 0.20 (power $=80 \%$ ), respectively. Based on a previous study ${ }^{(21)}$ and considering newborn weight at birth as a key variable, we considered $0.4 \mathrm{~kg}$ as standard deviation and $0.3 \mathrm{~kg}$ as the difference in the mean $(d)$. According to this, we needed twenty-six subjects in each group to have $80 \%$ study power. We included pregnant women aged 18-40 years who had been diagnosed with GDM by a 'one-step', 2 h oral glucose tolerance test with $75 \mathrm{~g}$ glucose load at 24-28 weeks' gestation. Exclusion criteria were multiple gestation, major fetal anomalies, current illicit drug use, continuous daily $\mathrm{Ca}$ and/or vitamin $\mathrm{D}$ intake since last menstrual period, insulin-dependent diabetes, smoking and history of kidney stones. Pregnant women without a previous diagnosis of glucose intolerance were screened. Diagnosis of GDM was done based on the criteria of the American Diabetes Association ${ }^{(22)}$; those whose plasma glucose concentration met one of the following criteria were considered as having GDM: fasting $\geq 5.1 \mathrm{mmol} / \mathrm{l}, 1 \mathrm{~h}$ post-load $\geq 10 \mathrm{mmol} / \mathrm{l}$ or $2 \mathrm{~h}$ post-load $\geq 8.5 \mathrm{mmol} / \mathrm{l}$. The present study was conducted according to the guidelines laid down in the Declaration of Helsinki and all procedures involving human subjects were approved by the ethics committee of Arak University of Medical Sciences. Written informed consent was obtained from all participants.

\section{Study design}

At study baseline and after stratification for preintervention BMI and weeks of gestation, GDM women were randomized to one of two treatment arms using computer-generated random numbers in a ratio of $1: 1$. A trained midwife at the maternity clinic, who was not blinded to the intervention, did the randomized allocation sequence, enrolled participants and assigned participants to interventions. The supplementation was started when the participants were between weeks 24 and 28 of their pregnancy. Although all participants were at this point of gestational age, participants were stratified based on their gestational age $(<26$ weeks, $>26$ weeks) before randomization. The women allocated to the $\mathrm{Ca}+$ vitamin $\mathrm{D}$ arm were advised to take calcium carbonate $1000 \mathrm{mg} / \mathrm{d}$ for 6 weeks plus a pearl containing $1250 \mu \mathrm{g}$ (50000 IU) of cholecalciferol (vitamin $\mathrm{D}_{3}$ ) twice during the study: at study baseline and day 21 of the intervention. The women allocated to the placebo arm were advised to take separate placebos for Ca (daily for 6 weeks) and for vitamin D (twice during the study: at study baseline and day 21 of the intervention), which were identical to the Ca tablets and vitamin D pearls in shape, colour and size. Ca supplement and its placebo were manufactured by Tehran Shimi Pharmaceutical Company (Tehran, Iran). Vitamin D and its placebo were manufactured by Dana Pharmaceutical Company (Tabriz, Iran) and Barij Essence Pharmaceutical Company (Kashan, Iran). Although the duration of the intervention was 6 weeks, all women were followed up until delivery. We did not continue the supplementation until delivery because we wanted to determine the effects of co-supplementation on pregnancy outcomes and were concerned that a large number of women would drop out if they were asked to provide blood near the end of their pregnancies. Participants were asked not to consume any supplements other than the one provided to them by the investigators. All participants were also consuming folic acid $400 \mu \mathrm{g} / \mathrm{d}$ from the beginning of pregnancy and ferrous sulfate $60 \mathrm{mg} / \mathrm{d}$ from the second trimester. Compliance to the $\mathrm{Ca}+$ vitamin D supplementation was assessed through quantification of serum Ca and vitamin D levels. The use of Ca+vitamin D supplements and placebos throughout the study was also checked by asking participants to bring the medication containers. Dietary information was assessed by a trained dietitian using a $3 \mathrm{~d}$ diet record (two weekdays and one weekend day) that 
was completed at week 1, 3 and 5 of the intervention. The dietary records were based on estimated values in household measurements. To obtain nutrient intakes of participants based on these $3 \mathrm{~d}$ food diaries, we used Nutritionist IV software (First Databank, San Bruno, CA, USA) modified for Iranian foods.

\section{Assessment of anthropometric measures}

Anthropometric measurements were conducted at baseline and after 6 weeks of intervention. Maternal height was measured using a daily calibrated stadiometer (Seca, Hamburg, Germany) to the nearest $0 \cdot 1 \mathrm{~cm}$ and weight was measured to the nearest $0 \cdot 1 \mathrm{~kg}$ using digital scales (Seca). Maternal BMI was calculated as weight in kilograms divided by the square of height in metres. Weight and length of all babies were measured in the labour ward following birth by a trained midwife using standard methods (Seca 155 scale). Infants' head circumference was measured to the nearest $1 \mathrm{~mm}$ with a Seca girth-measuring tape. We also determined infants' 1- and 5-min Apgar scores as another measure of pregnancy outcome. Preterm delivery was defined when delivery occurred at $<37$ weeks of pregnancy and newborn macrosomia was defined as birth weight $>4000 \mathrm{~g}^{(23)}$.

\section{Biochemical and polybydramnios assessment}

Ten millilitres of fasting blood were obtained from each participant after a 10-12 h overnight fast at study entry and at the end of the research at Arak reference laboratory. The blood samples were centrifuged and serum was stored at $-70^{\circ} \mathrm{C}$ until further assays. Commercial kits were used to measure fasting plasma glucose and serum Ca concentrations (Pars Azmun, Tehran, Iran). Participants underwent a $2 \mathrm{~h}$ oral glucose tolerance test and blood samples were collected at time 60 and $120 \mathrm{~min}$ to measure plasma glucose levels. Serum 25-hydroxyvitamin D concentrations were measured using a commercial ELISA kit (IDS, Boldon, UK). The inter- and intra-assay CV for serum 25-hydroxyvitamin D assays ranged from 4.5 to $7 \cdot 0 \%$. Hyperbilirubinaemia was considered when the total serum bilirubin level was at or above $15 \mathrm{mg} / \mathrm{dl}(257 \mathrm{~mol} / \mathrm{l})$ in infants 25 to $48 \mathrm{~h}$ old, $18 \mathrm{mg} / \mathrm{dl}(308 \mathrm{~mol} / \mathrm{l})$ in infants 49 to $72 \mathrm{~h}$ old, and $20 \mathrm{mg} / \mathrm{dl}(342 \mathrm{~mol} / \mathrm{l})$ in infants older than $72 \mathrm{~h}^{(24)}$. Polyhydramnios was diagnosed with a sonographic method after second vitamin D or placebo administration. On the basis of this measurement, polyhydramnios was defined as an amniotic fluid index in excess of $25 \mathrm{~cm}^{(25)}$.

\section{Statistical analysis}

To ensure the normal distribution of variables, histograms and the Kolmogorov-Smirnov test were applied. We used independent-samples Student's $t$ test to detect differences in baseline measures as well as in dietary intakes between the two groups. Pearson's $\chi^{2}$ test was used for comparison of categorical variables. To assess if the magnitude of change in dependent variables depended on the baseline maternal age, BMI and fasting plasma glucose, we controlled all analyses for baseline values of age, BMI and fasting plasma glucose to avoid potential bias. These analyses were done using two-factor repeated-measures ANOVA. $P<0.05$ was considered as statistically significant. All statistical analyses were done using the statistical software package SPSS 17.

\section{Results}

Nine hundred pregnant women attending maternity clinics affiliated to Arak University of Medical Sciences, Arak, Iran were screened for GDM and sixty patients were included in the clinical trial. Sixty GDM women in two groups were randomized to receive $\mathrm{Ca}+$ vitamin $\mathrm{D}$ or placebo. Finally, sixty participants ( $\mathrm{Ca}+$ vitamin $\mathrm{D}$ ( $n$ 30) and placebo ( $n$ 30)) completed the trial (Fig. 1). On average, the compliance rate in the present study was high, such that $100 \%$ of pearls and tablets were taken during the course of the study in both groups.

Mean age, pre-pregnancy weight and BMI was not statistically different between the two groups (Table 1). Baseline weight and BMI as well as post-intervention means of these variables were not significantly different between $\mathrm{Ca}+$ vitamin $\mathrm{D}$ and placebo groups. Participants who received $\mathrm{Ca}+$ vitamin $\mathrm{D}$ supplements had a significant rise in serum vitamin D level $(19.0 v .0 .5 \mathrm{ng} / \mathrm{ml}$, $P<0.001)$ and a trend towards a significant increase in serum Ca level $(0 \cdot 6 v \cdot-0 \cdot 1 \mathrm{mg} / \mathrm{dl}, P=0 \cdot 09)$ compared with the placebo group.

Based on the $3 \mathrm{~d}$ dietary records obtained throughout the intervention, no statistically significant difference was seen between the two groups in terms of dietary intakes of energy, fat, protein, carbohydrate, SFA, PUFA, MUFA, cholesterol, total dietary fibre, Ca and vitamin D (Table 2).

Women treated with $\mathrm{Ca}+$ vitamin $\mathrm{D}$ had a significant decrease in caesarean section rate $(23.3 \% v$. $63.3 \%$, $P=0.002)$ and maternal hospitalization (0 v. 13.3\%, $P=0.03$ ) compared with the placebo group (Table 3 ). In addition, newborns of GDM women randomized to Ca+vitamin D had no case of macrosomia, while the prevalence of macrosomia among those randomized to placebo was $13 \cdot 3 \%(P=0 \cdot 03)$. Lower rates of hyperbilirubinaemia $(20.0 \% v .56 .7 \%, P=0.03)$ and hospitalization (20.0\% v. $56.7 \%, P=0.03)$ were also seen in the supplemented group of newborns than in the placebo group. We did not find a significant difference in pre-eclampsia, maternal polyhydramnios, needing to progress to insulin therapy after the intervention, newborns' birth size and Apgar scores when comparing the two groups. Adjustment for baseline maternal age, BMI and fasting plasma glucose did not alter the findings. 


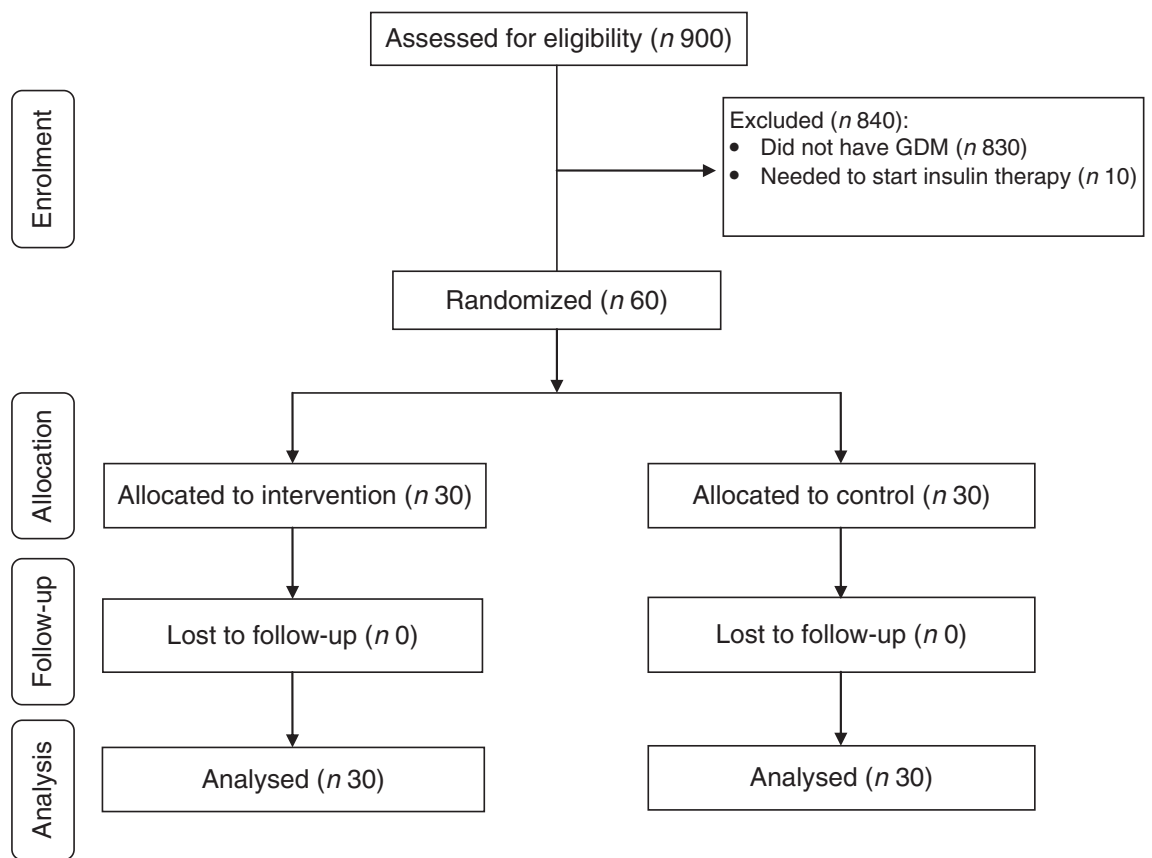

Fig. 1 Summary of patient flow in the present randomized, double-blind, placebo-controlled trial (GDM, gestational diabetes mellitus)

Table 1 General characteristics, serum calcium and vitamin D levels of the study participants: women with gestational diabetes mellitus and their newborns, Arak, Iran, March-July 2014

\begin{tabular}{|c|c|c|c|c|c|}
\hline & \multicolumn{2}{|c|}{ Placebo group* (n 30) } & \multicolumn{2}{|c|}{$\mathrm{Ca}+$ vitamin D groupt $(n 30)$} & \multirow[b]{2}{*}{$P$ value $\ddagger$} \\
\hline & Mean & SD & Mean & SD & \\
\hline Maternal age (years) & 31.6 & $6 \cdot 3$ & 28.7 & $6 \cdot 1$ & 0.06 \\
\hline Height $(\mathrm{cm})$ & 159.9 & 4.3 & $158 \cdot 2$ & 4.5 & 0.14 \\
\hline Weight pre-pregnancy $(\mathrm{kg})$ & 69.5 & 11.8 & $67 \cdot 7$ & $12 \cdot 0$ & 0.57 \\
\hline Weight at study baseline $(\mathrm{kg}) \S$ & $78 \cdot 1$ & 13.4 & 73.7 & $12 \cdot 8$ & 0.18 \\
\hline Weight at end of trial $(\mathrm{kg})$ & $80 \cdot 1$ & 13.0 & $75 \cdot 6$ & $12 \cdot 9$ & 0.18 \\
\hline Weight change $(\mathrm{kg})$ & 1.9 & 1.5 & 1.9 & 1.6 & 0.89 \\
\hline Weight at delivery (kg) & 83.3 & $12 \cdot 7$ & $80 \cdot 2$ & 11.6 & 0.31 \\
\hline Weight gain during pregnancy $(\mathrm{kg})$ & 13.8 & 4.2 & $12 \cdot 5$ & 3.5 & 0.17 \\
\hline BMI at study baseline $\left(\mathrm{kg} / \mathrm{m}^{2}\right)$ & 30.5 & 4.5 & 29.4 & 4.7 & 0.36 \\
\hline $\mathrm{BMI}$ at end of trial $\left(\mathrm{kg} / \mathrm{m}^{2}\right)$ & $31 \cdot 2$ & 4.4 & $30 \cdot 2$ & 4.7 & 0.37 \\
\hline BMI change $\left(\mathrm{kg} / \mathrm{m}^{2}\right)$ & 0.7 & 0.6 & 0.8 & 0.6 & 0.89 \\
\hline Gestational age before intervention (weeks) & $25 \cdot 6$ & 1.3 & 25.5 & 1.2 & 0.60 \\
\hline Follow-up duration (weeks) & $13 \cdot 0$ & 1.7 & $13 \cdot 1$ & 1.8 & 0.82 \\
\hline $\mathrm{Ca}$ at study baseline $(\mathrm{mg} / \mathrm{dl})$ & 8.2 & 1.3 & $8 \cdot 1$ & 1.7 & 0.87 \\
\hline $\mathrm{Ca}$ at end of trial $(\mathrm{mg} / \mathrm{dl})$ & $8 \cdot 1$ & 1.5 & 8.7 & 1.4 & 0.09 \\
\hline Ca change $(\mathrm{mg} / \mathrm{dl})$ & -0.1 & $1 \cdot 3$ & 0.6 & 1.9 & 0.09 \\
\hline Vitamin D at study baseline $(\mathrm{ng} / \mathrm{ml})$ & $20 \cdot 8$ & 14.4 & $17 \cdot 3$ & 10.9 & 0.29 \\
\hline Vitamin $\mathrm{D}$ at end of trial $(\mathrm{ng} / \mathrm{ml})$ & $21 \cdot 3$ & 14.4 & $36 \cdot 3$ & 21.3 & 0.002 \\
\hline Vitamin D change $(\mathrm{ng} / \mathrm{ml})$ & 0.5 & 6.0 & $19 \cdot 0$ & $18 \cdot 2$ & $<0.0001$ \\
\hline
\end{tabular}

${ }^{*}$ Received placebo for $\mathrm{Ca}$ (daily for 6 weeks) and placebo for vitamin $\mathrm{D}$ twice during the study: at study baseline and day 21 of the intervention. †Received calcium carbonate $1000 \mathrm{mg} / \mathrm{d}$ for 6 weeks plus a pearl containing $1250 \mu \mathrm{g}$ ( $50000 \mathrm{IU}$ ) of cholecalciferol (vitamin $\mathrm{D}_{3}$ ) twice during the study: at study baseline and day 21 of the intervention.

fObtained from an independent-samples Student's $t$ test.

\section{Discussion}

Our study demonstrated that Ca+vitamin D supplementation for 6 weeks among pregnant women with GDM at 24-28 weeks of gestation led to decreased caesarean section and maternal hospitalization rates, and decreased macrosomia, hyperbilirubinaemia and hospitalization in newborns compared with placebo; however, we did not find any significant effect on other indicators of pregnancy outcome. To our knowledge, the present study is the first one reporting the effect of $\mathrm{Ca}$ and vitamin $\mathrm{D}$ supplementation on pregnancy outcomes of women with GDM.

Women with GDM are a high-risk group for several complications including development of type 2 diabetes mellitus, metabolic syndrome and $\mathrm{CVD}^{(26)}$. 
Table 2 Dietary intakes of study participants throughout the study: women with gestational diabetes mellitus, Arak, Iran, March-July 2014

\begin{tabular}{|c|c|c|c|c|c|}
\hline & \multicolumn{2}{|c|}{ Placebo group* (n 30) } & \multicolumn{2}{|c|}{$\mathrm{Ca}+$ vitamin $\mathrm{D}$ group $\dagger(n 30)$} & \multirow[b]{2}{*}{$P$ value } \\
\hline & Mean & SD & Mean & SD & \\
\hline Energy (kJ/d) & 10205 & 707 & 10063 & 845 & 0.49 \\
\hline Energy $(\mathrm{kcal} / \mathrm{d})$ & 2439 & 169 & 2405 & 202 & 0.49 \\
\hline Fat $(\mathrm{g} / \mathrm{d})$ & 89.3 & 14.7 & 87.9 & 15.9 & 0.73 \\
\hline Protein $(g / d)$ & 86.6 & $7 \cdot 7$ & 87.0 & $16 \cdot 7$ & 0.89 \\
\hline Carbohydrate $(\mathrm{g} / \mathrm{d})$ & 331.6 & $32 \cdot 4$ & 324.6 & $46 \cdot 2$ & 0.50 \\
\hline SFA $(g / d)$ & $25 \cdot 9$ & $5 \cdot 6$ & $25 \cdot 8$ & 6.5 & 0.99 \\
\hline PUFA ( $(\mathrm{d} / \mathrm{d})$ & 28.9 & $8 \cdot 1$ & 27.9 & 7.0 & 0.60 \\
\hline MUFA $(\mathrm{g} / \mathrm{d})$ & 23.5 & $5 \cdot 1$ & 24.7 & $7 \cdot 3$ & 0.48 \\
\hline Cholesterol (mg/d) & 211.0 & $114 \cdot 8$ & 231.7 & 131.4 & 0.51 \\
\hline Total dietary fibre $(\mathrm{g} / \mathrm{d})$ & 18.9 & 4.9 & 17.5 & 4.9 & 0.23 \\
\hline $\mathrm{Ca}(\mathrm{mg} / \mathrm{d})$ & $1185 \cdot 1$ & $165 \cdot 2$ & 1139.5 & $134 \cdot 2$ & 0.24 \\
\hline Vitamin D $(\mu \mathrm{g} / \mathrm{d})$ & 3.0 & 0.8 & 2.8 & 0.9 & 0.41 \\
\hline
\end{tabular}

${ }^{*}$ Received placebo for $\mathrm{Ca}$ (daily for 6 weeks) and placebo for vitamin $\mathrm{D}$ twice during the study: at study baseline and day 21 of the intervention.

†Received calcium carbonate $1000 \mathrm{mg} / \mathrm{d}$ for 6 weeks plus a pearl containing $1250 \mu \mathrm{g}(50000 \mathrm{lU})$ of cholecalciferol (vitamin $\left.\mathrm{D}_{3}\right)$ twice during the study: at study baseline and day 21 of the intervention.

fObtained from an independent-samples Student's $t$ test.

Table 3 Effect of calcium plus vitamin D supplementation on pregnancy outcomes: women with gestational diabetes mellitus and their newborns, Arak, Iran, March-July 2014

\begin{tabular}{|c|c|c|c|c|c|}
\hline & \multicolumn{2}{|c|}{ Placebo group ${ }^{\star}(n 30)$} & \multicolumn{2}{|c|}{ Ca + vitamin D groupt $(n 30)$} & \multirow[b]{2}{*}{$P$ value } \\
\hline & $n$ or mean & $\%$ or SD & $n$ or mean & $\%$ or SD & \\
\hline Caesarean section, $n$ and $\%$ & 19 & $63 \cdot 3$ & 7 & $23 \cdot 3$ & $0.002 \ddagger$ \\
\hline Need to progress to insulin therapy after the intervention, $n$ and \% & 2 & $6 \cdot 7$ & 0 & 0 & $0.15 \ddagger$ \\
\hline Pre-eclampsia, $n$ and \% & 1 & $3 \cdot 3$ & 0 & 0 & $0.31 \neq$ \\
\hline Polyhydramnios, $n$ and \% & 5 & $16 \cdot 7$ & 1 & 3.3 & $0.08 \ddagger$ \\
\hline Maternal hospitalization, $n$ and $\%$ & 4 & $13 \cdot 3$ & 0 & 0 & $0.03 \ddagger$ \\
\hline Preterm delivery, $n$ and $\%$ & 1 & $3 \cdot 3$ & 2 & $6 \cdot 7$ & $0.55 \ddagger$ \\
\hline Macrosomia (birth weight $>4000 \mathrm{~g}$ ), $n$ and $\%$ & 4 & $13 \cdot 3$ & 0 & 0 & $0.03 \ddagger$ \\
\hline Gestational age (weeks), mean and SD & 38.6 & 0.2 & 38.6 & 0.2 & $0.83 \S$ \\
\hline \multicolumn{6}{|l|}{ Newborns' weight $(\mathrm{g})$, mean and SD } \\
\hline Crude & 3344.6 & $86 \cdot 5$ & $3286 \cdot 0$ & 64.9 & $0.58 \S$ \\
\hline Model 1 & $3339 \cdot 1$ & $76 \cdot 9$ & 3291.5 & $76 \cdot 9$ & $0.66 \|$ \\
\hline Model 2 & 3264.7 & $86 \cdot 6$ & 3323.9 & 79.9 & 0.639 \\
\hline \multicolumn{6}{|l|}{ Newborns' length $(\mathrm{cm})$, mean and SD } \\
\hline Crude & $50 \cdot 6$ & 0.3 & $50 \cdot 8$ & 0.3 & $0.52 \S$ \\
\hline Model 1 & $50 \cdot 6$ & 0.3 & 50.9 & 0.3 & $0.53 \|$ \\
\hline Model 2 & 50.7 & 0.4 & $50 \cdot 8$ & 0.4 & $0.96 \rrbracket$ \\
\hline \multicolumn{6}{|l|}{ Newborns' head circumference $(\mathrm{cm})$, mean and SD } \\
\hline Crude & $35 \cdot 6$ & 0.2 & $35 \cdot 1$ & 0.2 & $0.13 \S$ \\
\hline Model 1 & $35 \cdot 5$ & 0.2 & $35 \cdot 1$ & 0.2 & $0 \cdot 15 \|$ \\
\hline Model 2 & 35.4 & $0 . \overline{3}$ & $35 \cdot 2$ & 0.2 & 0.499 \\
\hline \multicolumn{6}{|l|}{ 1-min Apgar score, mean and SD } \\
\hline Crude & 9.0 & 0.04 & 9.0 & 0.03 & $0.56 \S$ \\
\hline Model 1 & 9.0 & 0.04 & $9 \cdot 0$ & 0.04 & $0.58 \|$ \\
\hline Model 2 & 8.9 & 0.04 & $9 \cdot 0$ & 0.04 & $0.25 \rrbracket$ \\
\hline \multicolumn{6}{|l|}{ 5-min Apgar score, mean and SD } \\
\hline Crude & 9.9 & 0.04 & 9.9 & 0.03 & $0.56 \S$ \\
\hline Model 1 & 9.9 & 0.04 & 9.9 & 0.04 & $0.58 \|$ \\
\hline Model 2 & 9.9 & 0.04 & $10 \cdot 0$ & 0.04 & $0.25 \pi$ \\
\hline Newborns' hyperbilirubinaemia, $n$ and \% & 17 & $56 \cdot 7$ & 6 & $20 \cdot 0$ & $0.03 \ddagger$ \\
\hline Newborns' hospitalization, $n$ and $\%$ & 17 & $56 \cdot 7$ & 6 & $20 \cdot 0$ & $0.03 \ddagger$ \\
\hline Newborns' hypoglycaemia, $n$ and $\%$ & 0 & 0 & 0 & 0 & $1.0 \ddagger$ \\
\hline
\end{tabular}

${ }^{*}$ Received placebo for $\mathrm{Ca}$ (daily for 6 weeks) and placebo for vitamin $\mathrm{D}$ twice during the study: at study baseline and day 21 of the intervention.

†Received calcium carbonate $1000 \mathrm{mg} / \mathrm{d}$ for 6 weeks plus a pearl containing $1250 \mu \mathrm{g}(50000 \mathrm{IU})$ of cholecalciferol (vitamin $\left.\mathrm{D}_{3}\right)$ twice during the study: at study baseline and day 21 of the intervention.

¥Obtained from Pearson's $x^{2}$ test.

§Obtained from an independent-samples Student's $t$ test.

IIObtained from two-way repeated-measures ANOVA adjusted for baseline maternal BMI.

TObtained from two-way repeated-measures ANOVA adjusted for baseline maternal age, BMI and fasting plasma glucose.

The findings of the present study showed that $\mathrm{Ca}+$ vitamin D supplementation among pregnant women with GDM resulted in decreased caesarean section rate and maternal hospitalization, but did not influence other pregnancy complications including pre-eclampsia, maternal polyhydramnios and needing to progress to insulin 
therapy after the intervention. In line with our study, vitamin D supplementation did not affect preterm delivery $^{(14)}$ and pre-eclampsia among healthy nulliparous women $^{(27)}$. Furthermore, in another study, vitamin D deficiency during pregnancy was associated with almost four times greater odds of primary caesarean section ${ }^{(13)}$. Higher serum Ca levels were also reported in pregnant women at the time of vaginal delivery compared with term women not in labour or women who did not go into labour but delivered by scheduled caesarean ${ }^{(28)}$. Nevertheless, data on the effect of combined Ca and vitamin D supplementation on maternal, perinatal or infant health outcomes in GDM patients are rare. In a study by Zhou et $a l .{ }^{(29)}$, no significant differences were found in terms of polyhydramnios, oligohydramnios, pre-eclampsia and caesarean section among pregnant women with different levels of vitamin D at 16-20-weeks' gestation. Reduced intracellular $\mathrm{Ca}$ signals and expression of $\mathrm{Ca}$ entry channels in uteruses from diabetic patients may result in a reduction in muscle content ${ }^{(30)}$, which in turn could reduce force and increase the caesarean section rate. In addition, macrosomia has also been reported as a risk factor for caesarean section in women with diabetes ${ }^{(31)}$. Furthermore, pure vitamin D deficiency, depending upon its chronicity, may induce hyperparathyroidism and consequent leaching of total bone $\mathrm{Ca}$ in order to maintain normocalcaemia, which might explain the initiation of early labour ${ }^{(13)}$.

The current study showed that taking $\mathrm{Ca}+$ vitamin D supplementation in GDM women led to decreased hyperbilirubinaemia and hospitalization in newborns. In agreement with our study, oral Ca supplementation resulted in a significant decrease in serum bilirubin in patients with Crigler-Najjar type $\mathrm{I}^{(32)}$. Furthermore, Miroliaee et $a l^{(33)}$ found that lower serum levels of vitamin D were associated with hyperbilirubinaemia in patients with non-cholestatic chronic liver disease. Fisher and Fisher $^{(34)}$ have also shown that serum vitamin D levels of less than $25 \mathrm{nmol} / \mathrm{l}$ could be a reliable predictor of higher serum bilirubin. In addition, improved liver enzyme levels were seen in the cord blood of infants whose mothers received one $1500 \mu \mathrm{g}$ dose of cholecalciferol in the second trimester or two $3000 \mu \mathrm{g}$ doses of cholecalciferol each in the second and third trimesters ${ }^{(35)}$. However, some investigators observed no evidence of vitamin D insufficiency in cirrhosis ${ }^{(36)}$, non-cirrhotic viral liver disease ${ }^{(37)}$ and haemochromatosis ${ }^{(38)}$. Several mechanisms can explain the effects of $\mathrm{Ca}$ and vitamin $\mathrm{D}$ supplementation on reducing newborns' hyperbilirubinaemia. Ca may act as a trapping agent for bilirubin in the intestine, thereby preventing back-diffusion across the intestinal wall ${ }^{(39)}$. Furthermore, the strong relationship between both the prevalence and degree of vitamin D insufficiency and the severity of chronic liver disease may indicate specific impairments of vitamin D metabolism in the liver. Impaired 25-hydroxylation of vitamin D in liver related to the degree of hepatic dysfunction has been reported in patients with alcoholic cirrhosis ${ }^{(40)}$. In rats, bile duct ligation led to a $64 \%$ decrease in hepatic 25 -hydroxylation of vitamin $\mathrm{D}^{(41)}$. In addition, the active form of vitamin $\mathrm{D}$ induces vitamin $\mathrm{D}$ receptors which in turn act as receptors for secondary bile acids, such as lithocholic acid and 3-ketocholanic acid, and result in their catabolism via induction of cytochrome $3 \mathrm{~A}$ enzymes ${ }^{(42,43)}$.

We did not find any significant effect of combined $\mathrm{Ca}+$ vitamin D supplementation on birth size. Our results are in agreement with previous studies showing that taking $1500 \mathrm{mg}$ Ca from week 20 of gestation among women with low $\mathrm{Ca}$ intake did not affect fetal and infant growth during the first year of life ${ }^{(44)}$. In addition, others did not observe any significant effect of vitamin D supplementation during pregnancy on birth size ${ }^{(21,45)}$. In contrast, some studies have indicated that either one oral dose of $1500 \mu \mathrm{g}$ cholecalciferol or two doses of $3000 \mu \mathrm{g}$ cholecalciferol in the second and third trimesters resulted in increased birth weight, length and head circumference ${ }^{(35)}$. Some studies that have been performed to determine the effect of maternal Ca status on birth size have generally reported larger birth weights with supplementation ${ }^{(46,47)}$. Discrepancies between our study and others might be explained by the different doses of Ca and vitamin D, different stages of gestation as well as the different durations of supplementation.

\section{Limitations of the study}

Our study has some limitations. First is the duration of this trial. We were unable to continue the $\mathrm{Ca}+$ vitamin $\mathrm{D}$ supplementation up to delivery time. Second, we did not assess the effects of $\mathrm{Ca}+$ vitamin $\mathrm{D}$ supplementation on other pregnancy outcomes including neonatal respiratory distress syndrome and $\mathrm{Ca}$ and vitamin $\mathrm{D}$ concentrations in amniotic fluid. Furthermore, in the current study, we did not assess cord blood levels of $\mathrm{Ca}$ and vitamin D. Further studies are suggested to determine the effect of $\mathrm{Ca}+$ vitamin D supplementation on cord blood levels of $\mathrm{Ca}$ and vitamin D. In the current study, we did not quantify serum vitamin D levels at the study baseline to see the percentage of women who were vitamin $\mathrm{D}$ deficient. Serum vitamin D levels were measured at the end of the trial to assess compliance to vitamin D supplements. When we found that some patients were vitamin D deficient (at the end of the study), we suggested they take vitamin D supplements. We calculated the sample size based on the primary outcome variable (newborn weight). Therefore, the study had enough power to detect differences for this parameter. However, we did not consider secondary outcome variables such as infant growth parameters or other pregnancy outcomes in the sample size calculation. As the study is not powered to detect differences in these outcome measures, one cannot make any conclusions about them. Therefore, further large-scale studies are needed to examine the effect of $\mathrm{Ca}+$ vitamin $\mathrm{D}$ supplementation on 
these pregnancy outcomes. Participants' dietary intakes were examined through the use of $3 \mathrm{~d}$ dietary records to find differences in dietary intakes between the two groups. We did not observe any significant difference in dietary intakes between the two groups. However, it must be kept in mind that all dietary assessment methods, including dietary records, are subject to bias particularly when the dietary information is collected from household information. This limitation should also be taken into account in interpretation of our findings.

\section{Conclusion}

In conclusion, $\mathrm{Ca}+$ vitamin D supplementation for 6 weeks among pregnant women with GDM led to decreased caesarean section rate and maternal hospitalization, and decreased macrosomia, hyperbilirubinaemia and hospitalization in newborns compared with placebo; however, we did not find any significant effect on pre-eclampsia, maternal polyhydramnios, needing to progress to insulin therapy after the intervention, newborns' birth size and Apgar scores.

\section{Acknowledgements}

Acknowledgements: The authors would like to thank the staff of Kossar Clinic (Arak, Iran) for their assistance in this project. Financial support: The present study was supported by the Vice-Chancellor for Research, Arak University of Medical Sciences, Arak, Iran (grant number 92-158). The funder had no role in the design, analysis or writing of this article. Conflict of interest: None. Authorship: M.K. and M.A-D. contributed in data collection and manuscript drafting. Z.A. and A.E. contributed in conception, design, statistical analysis and drafting of the manuscript. All authors read and approved the final version of the paper. Z.A. is the guarantor of this work; as such, he had full access to all data in the study and takes responsibility for the integrity of the data and the accuracy of the data analysis. This study is registered at the Iranian registry of clinical trials website (registration number IRCT201407115623N23; www.irct.ir). Ethics of buman subject participation: The present study was conducted according to the guidelines laid down in the Declaration of Helsinki and all procedures involving human subjects were approved by the ethics committee of Arak University of Medical Sciences. Written informed consent was obtained from all participants.

\section{References}

1. Prutsky GJ, Domecq JP, Sundaresh V et al. (2013) Screening for gestational diabetes: a systematic review and metaanalysis. J Clin Endocrinol Metab 98, 4311-4318.
2. Karcaaltincaba D, Kandemir O, Yalvac S et al. (2009) Prevalence of gestational diabetes mellitus and gestational impaired glucose tolerance in pregnant women evaluated by National Diabetes Data Group and Carpenter and Coustan criteria. Int J Gynaecol Obstet 106, 246-249.

3. Owens LA, O'Sullivan EP, Kirwan B et al. (2010) ATLANTIC DIP: the impact of obesity on pregnancy outcome in glucose-tolerant women. Diabetes Care 33, 577-579.

4. HAPO Study Cooperative Research Group (2010) Hyperglycaemia and Adverse Pregnancy Outcome (HAPO) Study: associations with maternal body mass index. BJOG 117, $575-584$.

5. Coustan DR (2014) Diagnosis of gestational diabetes. Scand J Clin Lab Invest Suppl 74, 27-33.

6. Asemi Z, Samimi M, Tabassi Z et al. (2013) A randomized controlled clinical trial investigating the effect of DASH diet on insulin resistance, inflammation, and oxidative stress in gestational diabetes. Nutrition 29, 619-624.

7. Reader DM (2007) Medical nutrition therapy and lifestyle interventions. Diabetes Care 30, Suppl. 2, S188-S193.

8. Asemi Z, Hashemi T, Karamali M et al. (2013) Effects of vitamin D supplementation on glucose metabolism, lipid concentrations, inflammation, and oxidative stress in gestational diabetes: a double-blind randomized controlled clinical trial. Am J Clin Nutr 98, 1425-1432.

9. Park HJ, Lee J, Kim JM et al. (2013) A study of snack consumption, night-eating habits, and nutrient intake in gestational diabetes mellitus. Clin Nutr Res 2, 42-51.

10. Whitelaw DC, Scally AJ, Tuffnell DJ et al. (2014) Associations of circulating calcium and 25-hydroxyvitamin D with glucose metabolism in pregnancy: a cross-sectional study in European and South Asian women. J Clin Endocrinol Metab 99, 938-946.

11. Bener A, Al-Hamaq AO \& Saleh NM (2013) Association between vitamin $\mathrm{D}$ insufficiency and adverse pregnancy outcome: global comparisons. Int J Womens Health 5, 523-531.

12. Hofmeyr GJ, Lawrie TA, Atallah AN et al. (2014) Calcium supplementation during pregnancy for preventing hypertensive disorders and related problems. Cochrane Database Syst Rev 6, CD001059.

13. Merewood A, Mehta SD, Chen TC et al. (2009) Association between vitamin D deficiency and primary cesarean section. J Clin Endocrinol Metab 94, 940-945.

14. Thorne-Lyman A \& Fawzi WW (2012) Vitamin D during pregnancy and maternal, neonatal and infant health outcomes: a systematic review and meta-analysis. Paediatr Perinat Epidemiol 26, Suppl. 1, 75-90.

15. Trumbo PR \& Ellwood KC (2007) Supplemental calcium and risk reduction of hypertension, pregnancy-induced hypertension, and preeclampsia: an evidence-based review by the US Food and Drug Administration. Nutr Rev 65, 78-87.

16. Asemi Z, Karamali M \& Esmaillzadeh A (2014) Effects of calcium-vitamin D co-supplementation on glycaemic control, inflammation and oxidative stress in gestational diabetes: a randomised placebo-controlled trial. Diabetologia 57, 1798-1806.

17. Asemi Z, Foroozanfard F, Hashemi T et al. (2014) Calcium plus vitamin D supplementation affects glucose metabolism and lipid concentrations in overweight and obese vitamin D deficient women with polycystic ovary syndrome. Clin Nutr (Epublication ahead of print version).

18. Tabesh M, Azadbakht L, Faghihimani E et al. (2014) Calcium-vitamin D cosupplementation influences circulating inflammatory biomarkers and adipocytokines in vitamin D-insufficient diabetics: a randomized controlled clinical trial. J Clin Endocrinol Metab 99, E2485-E2493.

19. Asemi Z, Taghizadeh M, Sarahroodi S et al. (2010) Assessment of the relationship of vitamin $D$ with serum antioxidant vitamins $\mathrm{E}$ and $\mathrm{A}$ and their deficiencies in Iranian pregnant women. Saudi Med J 31, 1119-1123. 
20. Tabrizi FM \& Pakdel FG (2014) Serum level of some minerals during three trimesters of pregnancy in Iranian women and their newborns: a longitudinal study. Indian J Clin Biochem 29, 174-180.

21. Roth DE, Perumal N, Al Mahmud A et al. (2013) Maternal vitamin $\mathrm{D}_{3}$ supplementation during the third trimester of pregnancy: effects on infant growth in a longitudinal followup study in Bangladesh. J Pediatr 163, 1605-1611.e3.

22. American Diabetes Association (2014) Diagnosis and classification of diabetes mellitus. Diabetes Care 37, Suppl. 1, S81-S90.

23. Boulet SL, Alexander GR, Salihu HM et al. (2003) Macrosomic births in the united states: determinants, outcomes, and proposed grades of risk. Am J Obstet Gynecol 188, 1372-1378.

24. Porter ML \& Dennis BL (2002) Hyperbilirubinemia in the term newborn. Am Fam Physician 65, 599-606.

25. Nobile de Santis MS, Radaelli T, Taricco E et al. (2004) Excess of amniotic fluid: pathophysiology, correlated diseases and clinical management. Acta Biomed 75, Suppl. 1, 53-55.

26. Noctor E, Crowe C, Carmody LA et al. (2015) ATLANTIC-DIP: prevalence of metabolic syndrome and insulin resistance in women with previous gestational diabetes mellitus by International Association of Diabetes in Pregnancy Study Groups criteria. Acta Diabetol 52, 153-160.

27. Haugen M, Brantsaeter AL, Trogstad L et al. (2009) Vitamin D supplementation and reduced risk of preeclampsia in nulliparous women. Epidemiology 20, 720-726.

28. Papandreou L, Chasiotis G, Seferiadis K et al. (2004) Calcium levels during the initiation of labor. Eur $J$ Obstet Gynecol Reprod Biol 115, 17-22.

29. Zhou J, Su L, Liu M et al. (2014) Associations between 25-hydroxyvitamin D levels and pregnancy outcomes: a prospective observational study in southern China. Eur J Clin Nutr 68, 925-930.

30. Al-Qahtani S, Heath A, Quenby S et al. (2012) Diabetes is associated with impairment of uterine contractility and high Caesarean section rate. Diabetologia 55, 489-498.

31. Ehrenberg HM, Durnwald CP, Catalano P et al. (2004) The influence of obesity and diabetes on the risk of cesarean delivery. Am J Obstet Gynecol 191, 969-974.

32. Van der Veere CN, Jansen PL, Sinaasappel M et al. (1997) Oral calcium phosphate: a new therapy for Crigler-Najjar disease? Gastroenterology 112, 455-462.

33. Miroliaee A, Nasiri-Toosi M, Khalilzadeh O et al. (2010) Disturbances of parathyroid hormone-vitamin $\mathrm{D}$ axis in non-cholestatic chronic liver disease: a cross-sectional study. Hepatol Int 4, 634-640.
34. Fisher L \& Fisher A (2007) Vitamin D and parathyroid hormone in outpatients with noncholestatic chronic liver disease. Clin Gastroenterol Hepatol 5, 513-520.

35. Kalra P, Das V, Agarwal A et al. (2012) Effect of vitamin D supplementation during pregnancy on neonatal mineral homeostasis and anthropometry of the newborn and infant. Br J Nutr 108, 1052-1058.

36. Floreani A, Zappala F, Fries W et al. (1997) A 3-year pilot study with 1,25-dihydroxyvitamin D, calcium, and calcitonin for severe osteodystrophy in primary biliary cirrhosis. J Clin Gastroenterol 24, 239-244.

37. Duarte MP, Farias ML, Coelho HS et al. (2001) Calciumparathyroid hormone-vitamin D axis and metabolic bone disease in chronic viral liver disease. J Gastroenterol Hepatol 16, 1022-1027.

38. Guggenbuhl P, Deugnier Y, Boisdet JF et al. (2005) Bone mineral density in men with genetic hemochromatosis and HFE gene mutation. Osteoporos Int 16, 1809-1814.

39. Van Der Veere CN, Schoemaker B, Bakker C et al. (1996) Influence of dietary calcium phosphate on the disposition of bilirubin in rats with unconjugated hyperbilirubinemia. Hepatology 24, 620-626.

40. Hepner GW, Roginsky M \& Moo HF (1976) Abnormal vitamin $\mathrm{D}$ metabolism in patients with cirrhosis. Am J Dig Dis 21, 527-532.

41. Bolt MJ, Sitrin MD, Favus MJ et al. (1981) Hepatic vitamin D 25-hydroxylase: inhibition by bile duct ligation or bile salts. Hepatology 1, 436-440.

42. Makishima M, Lu TT, Xie W et al. (2002) Vitamin D receptor as an intestinal bile acid sensor. Science 296, 1313-1316.

43. Xie W, Radominska-Pandya A, Shi Y et al. (2001) An essential role for nuclear receptors SXR/PXR in detoxification of cholestatic bile acids. Proc Natl Acad Sci U S A 98, 3375-3380.

44. Abdel-Aleem H, Merialdi M, Elsnosy ED et al. (2009) The effect of calcium supplementation during pregnancy on fetal and infant growth: a nested randomized controlled trial within WHO calcium supplementation trial. J Matern Fetal Neonatal Med 22, 94-100.

45. Hossain N, Kanani FH, Ramzan S et al. (2014) Obstetric and neonatal outcomes of maternal vitamin D supplementation: results of an open-label, randomized controlled trial of antenatal vitamin D supplementation in Pakistani women. $J$ Clin Endocrinol Metab 99, 2448-2455.

46. Villar J \& Repke JT (1990) Calcium supplementation during pregnancy may reduce preterm delivery in high-risk populations. Am J Obstet Gynecol 163, 1124-1131.

47. Lopez-Jaramillo P, Delgado F, Jacome P et al. (1997) Calcium supplementation and the risk of preeclampsia in Ecuadorian pregnant teenagers. Obstet Gynecol 90, 162-167. 